\title{
A Study on Object-oriented Adverbials in Mandarin from a Cognitive Perspective
}

\author{
Linze Li \\ College of International Studies, Southwest University, Chongqing, China
}

\begin{abstract}
The ubiquity and elusive nature of object-oriented adverbials in Mandarin has been a heated topic of discussions in the Chinese linguistic community. Scholars analyzed the syntactic manifestations and semantic constraints of this phenomenon and placed Semantic Orientation Theory at the core of the researches. It is claimed that object-oriented adverbials originate from and can be converted back to be the attribute of the object. From a cognitive perspective, this paper argues that different sentence patterns are different cognitive gestalts and have different pragmatic and discourse functions. It is concluded that (1) there is no conversional relations between the adverbials and attributes even though they are both semantically related to the object; (2) object-oriented adverbial sentences and attributive sentences represent different kinds of cognitive construal, the former being dynamic and sequential while the latter being stative and holistic; (3) grammatical metonymy is the fundamental cognitive mechanism for the seemly mismatch of form and meaning language and the cognitive basis of the Semantic Orientation Theory founded by Chinese scholars.
\end{abstract}

Index Terms -object-oriented adverbials, semantic orientation theory, grammatical metonymy

\section{INTRODUCTION}

A family of interesting natural language phenomena in Mandarin has long been overlooked by international linguistic community to the extent that it does not, till now, have a well-recognized English name. The ubiquity and elusive nature of such kind of linguistic manifestations did trigger a vast amount of researches in the Chinese literature (e.g. Zhu (1982), Sobelman \& Ho (1982), Lu (2003), Li (2007), etc.). However, most of these researches have been concerned with their syntactic manifestation and lexical constraints while their discourse function and cognitive mechanism are largely ignored. The following are some of the most frequently uttered sentences in daily lives and also repeatedly employed examples in the researches.

$\begin{array}{llllll}\text { (1) a. Ta } & \text { [nongnong de] } & \text { pao } & \text { le } & \text { yibei cha. } \\ 3 \mathrm{sg} & \text { [thick thick DE] } & \text { make } & \text { PERF } & \text { a cup tea. }\end{array}$

Lit.: He thickly made a cup of tea.

He made a cup of thick tea.

$\begin{array}{lllll}\text { b. Ta } & \text { [yuanyuan de] } & \text { hua le } & \text { yige } & \text { quan. } \\ 3 \text { sg } & \text { [roundround DE] } & \text { draw PERF } & \text { a } & \text { circle. }\end{array}$

Lit.: ? He roundly drew a circle.

He drew a round circle.

Despite of their syntactical adjacency to the predicate verb, the adverbials are semantically closely connected with the objects. Previous researches hold different views on how these adverbials should be addressed. Pan (1981) treated the adverbials in front of the verbs as attributes because they are closely related to the object and can be converted back to their original pre-nominal slot. Others (e.g. Zhu (1982), Zhang (2005), Lu \& Shen (2011), etc.) treated them as adverbials because of their placement in front of the verbs while admitting the fact that semantically they are closely related to the noun other than the verb in their adjacency. Still others (e.g. Lv (1986), Liu (1992), You (1999)) held a more dynamic view towards this phenomenon and claimed that the adverbials and attributes are convertible under certain conditions and, therefore, there are source sentences in the deep structure. However, the controversy of whether the attributive sentence or the adverbial sentence ${ }^{1}$ is the source sentence makes the issue even more complicated.

In accordance with the claims of the structuralism that different word orders means different sentence structures and the cognitive view that different sentences structures means different gestalts, we hold that the previous researches are flawed and have obvious shortcomings. From a cognitive perspective, we will prove that there is no conversional relationship between the attributive sentences and adverbial sentences despite of the occasional cases where an exchangeable relation seems existent. They are different syntactic patterns, conveying different meaning, having varying semantic and syntactic constraints and functioning differently in discourse.

From a cognitive view, the two sentence patterns represent different ways of construal. The adverbial sentence represents a dynamic construal of the static nature as represented by the attributive sentence. Grammatical metonymy is

\footnotetext{
${ }^{1}$ In this paper, adverbial sentences refer to sentences with object-oriented adverbials while attributive sentences refer to sentences whose object has an adjectival modifier that may be placed in the pre-verbal slot and function as an adverbial.
} 
the underlying cognitive mechanism that make different construal possible.

\section{Previous Researches on ObJect-oriented AdVERbials in Mandarin}

The relationship between form and meaning is the most important issue in the study of language. Generally speaking, form and meaning are pairs, with different linguistic forms conveying different meaning and functions varyingly. However, there seems to be exceptions in Mandarin where there are mismatches of form and meaning as exemplified by example (1). Instead of indicating the manner, time, place, etc. of the verb or the sentence at large, the pre-verbal adverbial closely relates to the object, which is usually at the end of the sentence, with the verb and modifiers in-between. Still there are far more similar sentences in Mandarin that point to an important source of productive language behavior that, until recently, has largely escaped the notice of researchers interested in meaning.

Chao (1968) named these mismatches between form and meaning as "skewed relations". Facing the failure to analyze such sentences with existent theories, Chinese scholars (e.g. Lv,1979; Shen,1983; Shao, 2004, etc.) devised the Semantic Orientation Theory, which is defined as the phenomenon where there are several possible modification relationships in a syntactic structure but only one of these relationships are possible (Shen, 2008). Further, four orientation categories are classified, namely, verb-to-noun orientation, noun-to-noun co-reference, modifier-to-head orientation and default element orientation. The current study focuses on the third category. It should be noted that we are using a quite different sense of the term Semantic Orientation against that in western linguistics as the attitude of a particular text toward a given subject, which can be further broken down into the evaluative factor (either positive or negative) and the potency (the degree to which the text is positive or negative) (see Lyons, 1977; Battistella, 1990).

Sentences including object-oriented adverbials has some sorts of nonstandard meanings or usages absent from dictionaries and grammar books and, typically, not computable by traditional linguists. Discussions focusing on how we treat these elements have been going on from the 80s of last century and different opinions had raised and can be classified into three categories.

Pan (1981) considered the adjectives in the adverbial slot to be attributes based on the fact that semantically they are closely connected with the object even though they are placed before the verb. The adjectives moved upwards (or leftwards) but the movement does not change their nature, i.e. the modifier of the object.

(2)a: guangkuode pingyuan dixia, [hengde, shude, zhide, wande], wa le bujiqishude didao.

Wide plain under, [vertical DE, horizontal DE, straight DE, curl DE] dig PERF numberless tunnel.

Lit.: Under the wide plain, vertical, horizontal, straight, curl, dug numberless tunnel.

Under the wide plain, numberless vertical, horizontal, straight and curly tunnels were dug.

b: Xue Lin chiwan le fan, you [yanyan de] he le jiwan cha.

Xue Lin eat over PERF meal, then [thick thick DE] drink PERF several bowls tea.

Lit.: Xue Lin had meal, and then thickly drank several bowls of tea.

Xue Lin had the meal and then drank a few bowls of thick tea.

For (2)a, it is claimed that because of the length of the adjectival phrases and their loose connection with the object, they can be moved forward without any change of meaning. For (2)b, it held that in order to emphasize the character of being thick, the attribute is moved forward, but the movement does not change its nature of being an attribute of the object. Zhang (1980) and Wen \& Luo (2000) held a similar view with Pan and claimed that attributes can be moved before verbs and, after the movement, they are still attributes.

Quite differently, some scholars tend to disagree with the previous conclusion and regard the moved attributes as adverbials (Zhu, 1982; Lu, 1982; Dai, 1982; Shao, 2007; etc.). Lu (1982) held that the adjectival phrases in (2) are all adverbials. In his view, the adjective phrases in (2)a form a parallel joint structure and they have an enumerative function. As regard to (2)b, "yanyande" (thickly)is an adverbial modifying the whole predicate-object structure. While holding the view that these adjectives or adjectival phrases as adverbials, they do not deny the close connection between the adverbials and the objects and try to prove its justification from the syntactic structure and the syntactic function of stative adjectives. Taking the so-called "skewed relation" between the syntactic structure and semantic structure of these sentences into consideration and facing the failure of analyzing these sentences with existent theories, scholars developed the Semantic Orientation Theory which we mentioned in part one and will address again in the fifth part of this study.

Still others (e.g. Lv, 1986; You, 1999, etc.) held a more dynamic view towards such phenomenon and claimed that the adverbial in the surface structure is actually the attribute in the deep structure while some claimed the contrary is true. It's quite safe to conclude that they consider the two kinds of sentence patterns as having a convertible relation and bear with them the same meaning. However, this view barely neglected the varying conditions for the formation of such sentences and their different discourse functions (Lu, 2003).

No study, however, has so far dealt with object-oriented adverbials with the cognitive approach. From the perspective of cognitive linguistics, a sentence represents a gestalt and, therefore, there is no convertible relations between the sentences. This view differs from the previous researches and will be backed up by facts in three aspects. Firstly, it is true that some of the adverbials can be placed before the object and vice versa, still there are cases where the conversion is impossible. Secondly, the adverbial sentences differs from the attributive sentences as each of them has divergent discourse functions. Thirdly, these two kinds of sentence have their subordinate categories and specific 
requirements and constraints for well-formedness and acceptability.

\section{Syntactic \& Semantic CONSTRAints of ObJECT-ORIENTED AdVERBials}

Scholars (e.g. Zhang, 1990; Zheng, 2000; Lu, 2003; Li, 2007) have taken a primarily semantic or syntactic approach to the constraints of the units in sentences with object-oriented adverbials. Different approaches and varying data led to different, sometimes contradictory, conclusions. In this study, both semantics and syntax are incorporated into the analysis of this phenomenon.

\section{A. Semantic Constraints}

An utterance is composed of many semantic units and each of these units plays a role in the overall meaning (Mary, 1999). As for sentences with object-oriented adverbials, the verbs and the adverbials bear with them the most important semantic roles and determine whether the sentence is acceptable or not.

Previous studies hold that the verbs in an adverbial sentence must be volitional and causative. Volition is considered as a synonym of intention in this case, a concept that distinguishes whether the action is intended by the subject/agent or not. It is claimed that only volition verbs are allowed in the adverbial sentences (Lu, 2003). The effect of this is such that when a volition verb is removed or changed, the meaning of the sentence will differ in same way or be unacceptable. And by causation, it indicates that the subject either causes someone or something to do or to be something, or causes a change in the state of the object. Thusly, the underlying situation of an adverbial sentence is that the causee or object undergoes an action or has its state changed with the effect of the predicate verb in a manner or way indicated by the adverbial. These two semantic constraints on the verb can account for the examples in (1). The actions are intentionally controlled and carried out and, as a consequence, the flavor and density of the coffee in (1)a and the outline of the cycle are changed in a preferable way as the subject intended. However, $\mathrm{Li}$ (2007) found that the following examples cannot be properly accounted for by these two semantic rules.

$\begin{array}{llll}\text { (3)a: ta } & \text { [rere de] } & \text { hele } & \text { yibei cha. } \\ 3 \text { sg } & {[\text { hot hot DE] }} & \text { drink PERF } & \text { a cup tea. }\end{array}$

Lit.: ? He [hotly] drank a cup of tea.

He drank a cup of hot tea.

b: Zhuozi shang [rere de] fang zhe yibei cha.

Table above [hot hot DE] place PCT a cup tea.

Lit.: ? On the table [hotly] placed a cup of tea.

On the table there placed a cup of hot tea.

$\mathrm{Li}$ (2007) examined the previous studies on the semantics of the predicates and found obvious shortcomings in the explanation of sentences as shown by example (3). Based on Guo's (1997) classification of verbs into three categories, namely, state verbs, action verbs and change verbs, it would be more appropriate to take action verbs as the categorical constraint for the verbs in adverbial sentences. Action verb is under the superordinate category of dynamic verbs which shows continued or progressive action over a span of time. It may has a perfective and durative aspect depending on whether there is a defined endpoint or not. Action verbs meet the requirement of process in adverbial sentences because of their temporal features and progressive nature.

Secondly, instead of claiming the objects' gradual change in state or coming into being under the effect of the action, it would be more appropriate to hold that the graduality of the feature of the object is another semantic constraint. Lu (2003) held that the object of the adverbials sentences has the feature of graduality, by which he means that the nature of the object changes in a continuous manner or the object itself come into being with the progressive process of the action. This generalization makes sense with most examples like (1), but fails to account for the following examples as shown in (4),

$\begin{array}{llllr}\text { (4): Ta } & \text { [yingying de] } & \text { mo dao } & \text { kuai } & \text { shitou. } \\ \text { 3sg } & \text { [hard hard DE] } & \text { touch PERF } & \text { piece } & \text { stone. }\end{array}$

Lit.: ? He [hardly] touched piece of stone.

He felt a piece of hard stone.

We agree with $\mathrm{Li}$ (2007) that, instead of the objects' graduality, it would be more appropriate to hold the graduality of the feature of the object as the semantic constraint. The action indicated by the verb changes the feature of the object or the feature is gradually felt as shown in (3)b and (4). In (3)b, one cannot judge whether the tea on the table is hot or not, but with wafting steam and other feature like water bubbling furiously with tea leaves rolling inside, the feature of being hot is felt with the careful observation. While in (4), the solidity of the stone is an innate nature, its hardness cannot be changed whether somebody touches it or not. But through repeated touches, the subject/agent can tell that the stone is hard. Therefore, it's quite safe to conclude that the gradual change or sensing of the feature of the object comprises the second semantic constraint of object-oriented adverbial sentences.

\section{B. Syntactic Constraints}

While the semantic constraints deal with the inherent requirements, the analysis of syntactic constraints of adverbial sentences will primarily focus on the particular requirements of the sentences units. From a syntactical 
approach, the adverbials and the semantically oriented object will be examined in this part.

From the modifiers of the objects in the examples listed in previous sections, it's safe to summarize that the objects are usually modified by $y i$ (one) or $j i$ (several). In some cases (e.g. (4)), yi is omitted. However, the omitted number does not change the meaning of the phrase and its grammatical function as show in (1), (2)b and (3). However, adverbial sentences whose object has large numbers as modifiers are not easily accepted by native speakers (see Li (2007)). The "a/an+quantifier+noun" structure is indefinite, with no fixed reference. Thusly, the usage of this structure undermines the importance of the object and it loses its statue of being the focus of the sentence. At the same time, the object-oriented adverbial is emphasized and become the communicational focus and pragmatic stress. In the regard of reference, the object in an attributive sentence bear more significance than that in an adverbial sentence. When the object appears in the structure "number + quantifier + noun" and the number is not $y i$ or $j i$, it is endowed with high individuality and clear reference, which will, in return, contradicts with the emphasis of the adverbial. That is the reason why the objects in adverbial sentences are usually appear in the " $y i / j i+$ quantifier + noun" structure.

The second syntactic constraint is about the form of the adjectives function as the adverbials. All the adjectives that appear in adverbial sentences are stative adjectives as classified by Zhu (1968) in their reduplicated forms. Reduplication appears most frequently to mark intensification on adjectives (Dixon, 2006). The existence of a link between reduplication and iconicity is often acknowledged and the link signifies a "quantitative" resemblance between form and meaning and views increase as the core meaning of reduplication: "an increase in form corresponds with an increase in the projected referent(s) of the form" (Conradie, 2003: 203).

Reduplicated adjectives in Mandarin take with them connotation of high affection and volition, which make perfect match with adverbial sentences. Firstly, as for volition or purpose, the property as represented by the reduplicated adjectives has the feature of [+controllability], it is a state that the agent want to achieve. Take (1)a and (4)c for example, by intentionally prolonging the time of heat, the porridge become thicker and thicker and by adding more tea leaves and keep leaves in the hot water for a longer time, the agent get thicker tea. It also should be noted that all the adjectival adverbials are heterogeneous, with opposite states at the each ends of the pole and have endless in-between states. By intentional control, the subject/agent can change quality or state of the object by acting purposefully on them. Secondly, the reduplicated adjectives have different degrees of subjectivity when they are placed on the adverbial slot and the attributive slot. When they function as adverbials, the sentence indicates strong subjectivity or an intensified readying in terms of quantity or continuity.

\section{AdVerbial Sentences vs Attributive Sentences}

Chapter III focuses on the semantic and syntactic constraints for the well-formedness of adverbial sentences. Some of these constraints have been taken as criteria for the successful conversion of attributive sentences to adverbials sentences. This chapter is concerned with the differences between adverbial sentences and attributive sentences. The so-called conversional relationship will be examined.

\section{A. Sentence Conversion}

The close connection between the object-oriented adverbial and the object makes the intuitional inference that adverbial sentences are converted from attributive sentence quite reasonable. Some scholars (e.g. Zhang, 2005) claim that for every adverbial sentence, there is an original or source attributive sentence. For repeated use of adverbial sentences, the source sentence may disappear and no longer be used. In actuality, in line with the structuralism and cognitive linguistics, different word orders indicate different sentences patterns which in turn forms different gestalts, which reflect different ways of recognizing this world. We base our claim that the so-called convertible adverbial sentences and attribute sentences are different syntactic patterns on the fact that not all attributive sentences can be converted into adverbial sentences and vice versa.

(4) a: ta rengguolai yige [honghongde] pingguo. $\rightarrow$ *ta [honghong de] rengguolai yige pingguo.

3 sg throw PERF an [redred DE] apple. $\rightarrow * 3$ sg [redred DE] throw PERF an apple

Lit.: He threw here a [red red] apply. $\rightarrow *$ He [red red -ly] threw here an apple.

He threw here a very red apply. $\rightarrow *$ He red-ly threw here an apple.

b: ta [heihei de] ranle toufa. $\rightarrow$ ta ranle [heihei de] toufa.

3 sg [blackblack DE] dye PERF hair. $\rightarrow 3$ sg dye PERF [black black DE] hair.

Lit.: He [black black-ly] dyed hair. $\rightarrow$ He dyed [very black] hair.

He dyed his hair deep black. $\rightarrow$ He dyed his deep black hair to other color./He dyed his hair deep black.

c: ta [chouchoude] aole guo zhou. $\rightarrow$ He aole guo [chouchou de] zhou.

3sg [thickthick DE] boil PERF pot porridge. $\rightarrow$ 3sg boil PERF pot [thick thick DE] porridge.

Lit.: He [thickly] boiled a pot of porridge. $\rightarrow$ He boiled a pot of [thick] porridge.

He thickly boiled a pot of porridge. $\rightarrow$ He boiled a pot of thick porridge. (Lu, 2003)

The converted sentence of (4)a is unacceptable because of the semantic incompatibility between the adverbial and the verb. The converted sentences of (4)b and (4)c are acceptable, but differences still exist between the two because the connotations and even truth values are not equal. The original adverbial sentence of (4)b has only one meaning and can be paraphrased as that his hair was not deep black and for some purposes, he intentionally dyed his hair black. The 
sentence conveys strong intention and purpose. However, the converted sentence in (4)b has two different readings as shown by the English translation, one being that his hair had been black and he changed it into different colours and the other being that he dyed his hair deep black. The reduplicated adjective "heiheide" intensifies the degree of black in the second reading.

The sentences in (4)c have been considered as having the same meaning and taken as one of the best examples of attributive-adverbial conversion. This kind of sentences have arose most controversies and been the subject of heated discussions. We hold that the conclusion can only be true in the regards of semantic meaning and truth values. However, with regard to pragmatic meaning, the adverbial sentence is endowed with strong intention and the property of being thick is highly expected and carefully controlled during the process of cooking. While the attributive sentence is prone to be an objective report of the state of the porridge.

\section{B. Discourse Functions}

With regard to discourse functions, Li (2007) investigated the attributive sentences and adverbial sentences and pointed out that the noun phrase (including the head of the phrase, i.e. object) in attributive sentence has high topical continuity and frequently functions as the theme of the following text, being the repeated target of anaphoric reference. From the view of information structure, the noun phrase is new information (also see Chen (1987)) and always functions as the topic of the following discourse. Surveys (Li, 2007) show that nearly $70 \%$ of the noun phrases acting as objects in the adverbials sentence are incidental elements in the discourse and seldomly be referred to in the following discourse. More often than not, the adverbial sentences function as the background information in discourse. Moreover, $25 \%$ of object-oriented adverbials are used in the manner adverbial clauses, which is even more typical of being as background information.

\section{A Grammatical Metonymic Account}

From the stative modifying attribute to the dynamic adverbial, the change signifies different ways of construal: the holistic scan of the object and/or its properties and the sequential scan of the gradual naissance or sensing of the object and/or its characteristics. This chapter will focus on the mechanism of how different expressions are possible and hold that the formation of different expressions are the results of construal.

\section{A. Grammatical Metonymy}

In this part, we will mainly address on the mechanism of object-oriented adverbials' coming into being with a brief introduction of the grammatical metonymy first.

After the seminal work co-authored by Lakoff and Johnson in 1980, which triggered a vast amount of research on the role of metaphor and metonymy in conceptualization, scholars came to realize that metonymy may be a more fundamental cognitive phenomenon than metaphor (Panther \& Radden, 1999). In the Chinese literature, Shen (1999) claimed that grammatical metonymy refer to the grammatical manifestation of metonymy, which is a general cognitive phenomenon.

Based on the degree of abstractness, Ruiz de Mendoza \& Diez (2001) classified metonymy into high-level metonymy and low-level metonymy. And grammatical metonymy is a high-level metonymy which has consequences in terms of linguistic structure. Based on the research of the metonymic motivation of a vast amount of grammatical phenomena, Ruiz de Mendoza \& Pena (2008:251) defined grammatical metonymy as "a form of generic or high-level metonymy that has consequences in terms of morphological and/or syntactic structure". While Panther \& Thornburg (2009:16) define grammatical metonymy as conceptual metonymy that motivates distributional properties of function words, grammatical morphemes, and word classes. Based on the study of Chinese syntactic structures, Wu (2013:40) defines grammatical metonymy as conceptual metonymy which effects the syntactic distribution of elements and the formation of the whole syntactic structure. She claims that the purpose of grammatical metonymic research is to reveal the cognitive mechanism of metonymy of syntactic structure and how it effects syntactic structure.

The Semantic Orientation Theory mentioned in Chapter I reveals the semantic relation of syntactic units and provides a new approach to the research of meaning. However, the confirmation of the semantic relationship between different sentence elements is rather intuitional. That is, the theory is weak in explaining why the separated united are connected instead of the adjacent ones. From a cognitive perspective, we hold that the mechanism underlying the semantic orientation or link is grammatical metonymy. In the following part, two grammatical metonymies are deployed to address this phenomenon.

\section{B. Property for Intention to Achieve That Property}

The most commonly used grammatical metonymy for object-oriented adverbial sentences is PROPERTY FOR INTENTION TO ACHIEVE THAT PROPERTY. Examples as (1), (4)b and (4)c belongs to this metonymy. The adjectives representing the property are intentionally used as adverbials, and through the action as indicated by the verb, the object is controlled or caused to have that property. This grammatical metonymy is reflected in our everyday language by a wide variety of expressions, e.g. "nongnongde" (thickly), "yuanyuande" (?roundly), "cuicuide" (crisply), etc.. The descriptive nature of adjectives determines that the link between adjectives and nouns are customary. When 
people use the adjectives, which are usually placed in the pre-nominal slot, as pre-verbal adverbials via grammatical metonymy, the meaning and function of these adjectives change. Instead of describing the stative property of the object as it is usually conceived, these adjectives, by functioning as adverbials, implies strong intention to achieve that property.

\section{Property for Sensing That Property}

Another type of the object-oriented adverbials is not about the change of the object or the property of the object as exemplified by (5). The property donated by the adjectives is not the intentional result of the predicate verb, but the pre-existent property of the object. Semantic analysis shows that the difference between the two is that instead of changing the state of the object, the subject gradually figure out the feature of the object. The gradual process of recognizing feature through the action denoted by the verb is the main difference between the adjective's attributive and adverbial uses.
(5) a: Ta [yingying de] caizhe kuai shitou.
3sg [hard hard DE] step PERF piece stone.
Lit.: ? He hardly stepped a piece of stone.
He stepped on and felt a hard stone.
$\begin{array}{cccc}\text { b: Ta } & \text { [ruanruan de] } & \text { modao yige dongxi. } \\ 3 \text { sg } & \text { [soft soft DE] } & \text { touch PERF a } & \text { thing. }\end{array}$
Lit.: ? He softly touched a thing.
He touched a soft thing.

The stone in (5)a is hard not because he stepped on it. The property of being hard is gradually felt through the action of stepping on it. Also, confirmation of the soft texture of the thing in (5)b comes from repeated touching.

\section{CONCLUSION}

This paper has been committed to the cognitive analysis of object-oriented adverbials in Mandarin. It argues that adverbial sentences and attribute sentences are two different syntactic patterns from a cognitive view and strongly oppose the traditional view that they are convertible sentences. Semantic and syntactic approaches both are incorporated into the analysis of the constraints of adverbial sentences. It is pointed out that the two sentence patterns represent two different gestalts and different construal. With grammatical metonymy, the semantic link of separated sentences units, or the so-called "skewed relationship between form and meaning" are addressed in a proper way and it provides a cognitive basis for the Semantic Orientation Theory.

This paper offers a different perspective on the analysis of the object-oriented adverbials in Mandarin and provides new evidence to the cognitive claim that different sentences are different gestalts and even the slightest change of form brings the change of meaning. It's expected that it could shed some light on the research of syntax-semantics interface within one language and typological researches between different languages.

\section{ACKNOWLEDGEMENTS}

Special thanks to Francisco J. Ruiz de Mendoza, a renowned world-famous cognitive linguist from Spain, for his insightful suggestions on this paper.

\section{REFERENCES}

[1] Battistella, E. L. (1990). Markedness: The Evaluative Superstructure of Language. New York: State University of New York Press.

[2] Conradie, C. J. (2003). The iconicity of Afrikaans reduplication. In Wolfgang G. Müller, Olga Fischer (Eds.), From sign to signing: iconicity in language and literature, Amsterdam/Philadelphia: John Benjamins Publishing Company, 203-224.

[3] Chao, Y. R. (1968). A Grammar of Spoken Chinese. Beijing: The Commercial Press.

[4] Chen, P. (1987). A study on the four groups of concepts related to nominal elements in Mandarin. Studies of the Chinese Language, 2, 96-105.

[5] Dai, H. Y. (1982). Additional discussion of "Rere de he yi wan cha". Journal of Chinese Linguistics, 10, 81-85.

[6] Dixon, R. M. W. \& A. Y. Aikhenvald. (2006). Adjective Classes: A Cross-Linguistic Typology. Oxford: Oxford University Press.

[7] Guo, R. (1997). Process and Non-process---two extrinsic temporal features of Chinese predicates. Studies of the Chinese Language, (3), 162-175.

[8] Li, F. J. (1983). An analysis of attribute movement. Studies of Chinese, 3, 24-31.

[9] Li, J. R. (2007). A functional analysis of sentences with object-oriented adverbial. Studies of the Chinese Language, 4, 331-342.

[10] Liu, D.W. (1992). Semantic entailment and the movement of Modifiers. Chinese Teaching in the World, 1, 17-22.

[11] Lu, J. (2003). An analysis on the syntactic realization and function of Chinese depictive adverbial modifiers. Studies in Language and Linguistics, 23, 99-106.

[12] Lu, J. M. (1982). On the issue of attribute movement. Studies of the Chinese Language, 3, 179-181.

[13] Lu, J. M., \& Y. Shen. (2011). 15 lectures on Chinese and Chinese study. Beijing: Peking University Press.

[14] Lu, Z. (2003). An analysis on the syntactic realization and function of Chinese depictive adverbial modifiers. Studies in 
Language and Linguistics, 1, 100-106.

[15] Lv, S. X. (1979). Issues on Chinese grammatical analyses. Beijing: The Commercial Press.

[16] Lv, S. X. (1986). Flexibility of Chinese syntax. Studies of the Chinese Language, 1, 15-26.

[17] Lyons, J. (1977). Semantics (vol.1). Cambridge: Cambridge University Press.

[18] Mary, D. (1999). Semantics and syntax in lexical functional grammar: The resource logic approach. Cambridge, MA: MIT.

[19] Pan, X. D. (1981). A study of the movement of attributes. Studies of the Chinese Language, (4), 54-61.

[20] Panther, K. U. \& L. Thornburg. (1999). The potentiality for actuality metonymy in English and Hungarian. In K.U. Panther \& G. Radden (Eds.). Metonymy in language and thought. Amsterdam/Philadelphia: John Benjamins Publishing Company, 333-357.

[21] Panther, K. U. \& L. Thornburg. (2009). Introduction: On figuration in grammar. In K.U. Panther \& L. Thornburg \& A. Barcelona (Eds.). Metonymy and metaphor in grammar. Amsterdam/Philadelphia: John Benjamins Publishing Company, 1-44.

[22] Ruiz de Mendoza, I. F. J. \& M. Pena. (2008). Grammatical metonymy within the action frame in English and Spanish. In Maria De Los Angeles Gomez Gonzalez (Eds.). Current trends in contrastive linguistics: Functional and cognitive perspectives. Amsterdam \& Philadelphia: John Benjamins Publishing Company, 251-280.

[23] Ruiz de Mendoza. I. F. J. \& O. I. Diez. (2001). High-level metonymy and linguistic structure. Unpublished draft. http://sincronia.cucsh.udg.mx/metonymy.htm (accessed 17/7/2019).

[24] Shao, J. M. (2007). A Study of Chinese Grammar. Beijing: The Commercial Press.

[25] Shen, Y. (2008). The semantic orientation theory and its application in the study of Chinese syntactic elements. In Shen, Y. \& S. L. Feng. (Eds.). Contemporary linguistic theories and related studies on Chinese. Beijing: The Commercial Press, 321-344.

[26] Sheng, J. X. (1999). A metonymic model of transferred designation of de-constructions in Mandarin Chinese. Contemporary Linguistics, 1, 3-15.

[27] Sobelman, C.P., \& Ho Chi-yu. (1982). "Rere de he yi wan cha"---A study note and related questions. Journal of Chinese Linguistics, 10, 52-76.

[28] Wen, S.L. \& Z.Q. Luo. (2000). Movement of attribute. Journal of Shanxi University, 4, 74-78.

[29] Wu, S. Q. (2013). A study of grammatical metonymy based on the analysis of Chinese syntactic structures. Beijing: China Social Sciences Press.

[30] You, L. (1999). An Analysis of adverbial-converted attributes. Journal of Shandong University, 3, 94-98.

[31] Zhang, G. X., (2005). Semantic Orientation of Characters and Pragmatic motivation of syntactic movements. Studies of the Chinese Language, 1, 16-28.

[32] Zhang, J. (1980). Modern Chinese: A new version. Shanghai: Shanghai Education Publishing House.

[33] Zhang, L. J. (1990). On the Semantic Orientation of A in "NP1+A+VP+NP2". Journal of Yantai University, 3, 87-96.

[34] Zhen, G. Y. (2000). A study of the orientation of adjective in the adverbial slot in mandarin. Wuhan: Central China Normal University Press.

[35] Zhu, D.X. (1982). Lectures on Grammar. Beijing: The Commercial Press.

Linze Li received his Master's degree in English Language and Literature from Southwest University, China in 2011. He is currently a lecturer and Ph.D. candidate in the College of International Studies in the same university. His research interests include Cognitive Linguistics, Second Language Acquisition and Linguistic Typology. 